\title{
Association between EGFR Gene Mutation and Antioxidant Gene Polymorphism of Non-Small-Cell Lung Cancer
}

\author{
Ching-Hsiung Lin ${ }^{1,2,3,+} \oplus$, Po-Jen Yang ${ }^{4,5,+}$, Sheng-Hao Lin ${ }^{1,2,3}$, Kun-Tu Yeh ${ }^{4,6} \oplus$, \\ Thomas Chang-Yao Tsao ${ }^{4,7}$, Yu-En Chen ${ }^{6}$, Shu-Hui Lin ${ }^{6,8, * \mathbb{D}}$ and Shun-Fa Yang 9,10,*(D) \\ 1 Division of Chest Medicine, Department of Internal Medicine, Changhua Christian Hospital, Changhua 500, \\ Taiwan; 47822@cch.org.tw (C.-H.L.); 112364@cch.org.tw (S.-H.L.) \\ 2 Institute of Genomics and Bioinformatics, National Chung Hsing University, Taichung 402, Taiwan \\ 3 Department of Recreation and Holistic Wellness, MingDao University, Changhua 500, Taiwan \\ 4 School of Medicine, Chung Shan Medical University, Taichung 402, Taiwan; cshy1030@csh.org.tw (P.-J.Y.); \\ 10159@cch.org.tw (K.-T.Y.); tcyt@csmu.edu.tw (T.C.-Y.T.) \\ 5 Department of Family and Community Medicine, Chung Shan Medical University Hospital, \\ Taichung 402, Taiwan \\ 6 Department of Surgical Pathology, Changhua Christian Hospital, Changhua 500, Taiwan; 182242@cch.org.tw \\ 7 Division of Chest, Department of Internal Medicine, Chung Shan Medical University Hospital, \\ Taichung 402, Taiwan \\ 8 Department of Medical Laboratory Science and Biotechnology, Central Taiwan University of Science \\ and Technology, Taichung 402, Taiwan \\ 9 Institute of Medicine, Chung Shan Medical University, Taichung 402, Taiwan \\ 10 Department of Medical Research, Chung Shan Medical University Hospital, Taichung 402, Taiwan \\ * Correspondence: 74630@cch.org.tw (S.-H.L.); ysf@csmu.edu.tw (S.-F.Y.) \\ + These authors contributed equally to this work and should be considered as co-first authors.
}

Received: 31 July 2020; Accepted: 11 September 2020; Published: 14 September 2020

check for updates

\begin{abstract}
EGFR mutation status is considered as an important predictor of therapeutic responsiveness in non-small-cell lung carcinoma patients. Recent evidence suggests that antioxidant gene polymorphisms are potential predictors of lung cancer risk. Thus, stratification of EGFR mutation-related phenotypes by antioxidant gene polymorphism status can be an effective approach in terms of improving the prognosis of lung cancer patients. The present study was designed to evaluate the distribution frequency of antioxidant gene polymorphisms in lung adenocarcinoma, as well as its association with hotspot EGFR mutations. The study findings revealed that a statistically significant association exists between EGFR L858R mutation and AG + GG genotypes of SOD rs4880 polymorphism. Furthermore, the subgroup analysis data revealed that compared to AA genotype of SOD rs4880, AG + GG genotypes were significantly associated with advanced cancer stage and distant metastasis. Taken together, these findings can be utilized clinically to predict cancer aggressiveness, metastatic, potential and therapeutic responsiveness of lung cancer patients.
\end{abstract}

Keywords: adenocarcinoma; EGFR mutation; antioxidant gene polymorphisms

\section{Introduction}

Lung cancer is the leading cause of death worldwide. It is a highly invasive and metastatic cancer with very poor prognosis. The death rate associated with lung cancer is higher than that observed in colon, breast and pancreatic carcinomas, and the 5-year survival rate of lung cancer is lower than 18\% [1]. Among all lung cancer types, small-cell lung carcinoma and non-small-cell lung 
carcinoma (squamous-cell carcinoma, adenocarcinoma, and large-cell carcinoma) account for $15 \%$ and $85 \%$, respectively [2].

Epidermal growth factor receptor (EGFR) is a transmembrane protein with a tyrosine kinase domain in the intracellular portion. It plays important roles in regulating various physiological functions, including cell proliferation and migration [3]. Activating mutations in EGFR gene are observed frequently in non-small-cell lung carcinoma patients [4], and EGFR gene polymorphisms are associated with the risk of lung cancer [5]. It is well-documented that the most common EGFR mutations including exon 19 deletions and L858R mutations strongly predict the sensitivity of lung cancer patients to tyrosine kinase inhibitor treatments [6]. Moreover, studies conducted on erlotinib-treated lung cancer patients with EGFR mutations have shown that a specific polymorphism (181946C > T) in EGFR gene is associated with long-term progression-free and overall survival [7].

Reactive oxygen species (ROS) are produced as a byproduct of cellular respiration and act as a second messenger in various signaling pathways. However, excessive production of ROS can lead to initiation of a series of cellular reactions that ultimately cause oxidative stress and inflammation, which are two hallmarks of cancer onset and progression [8]. To counterbalance the burden of increased ROS, there are a wide variety of nonenzymatic antioxidants, such as glutathione, carotenoids, flavonoids and vitamins $\mathrm{A}, \mathrm{C}$ and $\mathrm{E}$, as well as enzymatic antioxidants, such as superoxide dismutase (SOD), catalase (CAT), glutathione peroxidase (GPX) and thioredoxin (TRX) [8].

A number of studies have been conducted to evaluate the effect of antioxidant system on cancer progression and recurrence [9]. In this context, one interesting study revealed that production of glutathione is a prerequisite for cancer onset, but not for cancer progression [10]. Moreover, the study has pointed out that inhibition of both glutathione and TRX signaling pathways can induce cancer cell apoptosis. The activity of antioxidant system is particularly important in lung carcinomas as lung tissue is highly susceptible to oxidative stress-induced damage [11]. One recent study has demonstrated that the activities of different SOD isotypes and catalase are low in lung cancer cells than adjacent normal cells; however, the activities of GPX, glutathione reductase, and glutathione S-transferase are higher in lung cancer cells [12].

Genetic polymorphisms of cellular antioxidants are known to play a significant role in the pathogenesis of various oxidative stress- and inflammation-related diseases, such as cancer [13-16]. Recently, a meta-analysis study has stated that catalase C262 T polymorphism is associated with an increased risk of prostate cancer [17]. Similarly, polymorphisms in SOD gene is associated with the onset of different cancer types, including lung and colorectal cancers [18]. In case of lung cancer, one study has shown that glutathione S-transferase T1 gene polymorphism is associated with the lung cancer risk [19]. Similarly, manganese SOD (MnSOD) gene polymorphisms (Ala16Val) together with the smoking status are known to be associated with an increased risk of lung cancer [20]. In EGFR-mutated non-small-cell lung cancer patients treated with tyrosine kinase inhibitors, genetic polymorphisms of glutathione S-transferase P1, myeloperoxidase and biliverdin reductase A have been shown to be associated with a reduced overall survival [21]. Interestingly, it has been found that EGFR-overexpressing breast cancer cells can develop resistance against tyrosine kinase inhibitors due to an increased cellular ROS level, indicating that antioxidant-mediated elimination of excessive ROS can be a potential strategy to treat patients with EGFR-mutated carcinomas [22]. Previous studies showed association between SNPS and antioxidant genes in various cancer types, including breast, prostate, colon and lung cancer [23-25]. These SNPs affect protein or mRNA expression in human cancers. Based on these study, in this present study we aimed to explore the correlation between SNPs and EGFR mutation in NSCLC patients.

\section{Materials and Methods}

\subsection{Patients}

A total of 314 patients with lung adenocarcinoma (age range: 30-70 years) were recruited for the present study. Of all patients, 117 had lung adenocarcinoma with wild-type EGFR and 197 had 
EGFR-mutated lung adenocarcinoma. Demographic characteristics and medical information of the patients, including gender, smoking status, AJCC clinical staging, tumor ' $\mathrm{T}$ ' classification, lymph node status, distant metastasis, and tumor differentiation, were obtained from their medical records. For EGFR gene sequencing, paraffin-embedded cancer tissues were collected; in addition, whole blood samples were collected from the participants and kept in EDTA-containing sterile tubes for genotyping. This study was approved by the Institutional Review Board (IRB) of Changhua Christian Hospital at Changhua (IRB No. 140205, date of approval 9 March 2014) and Cheng-Ching General Hospital (No. HP120009, 22 September 2012).

\subsection{EGFR Mutation Testing}

Paraffin-embedded tumor tissues were used to extract DNA using cobas ${ }^{\circledR}$ DNA Sample Preparation Kit (Roche, Indianapolis, IN, USA). Real-time quantitative PCR (high resolution melting analysis) analyzed with cobas ${ }^{\circledR}$ Z480 (Roche, Basel, Switzerland). The cobas EGFR Mutation Test v2 can identify 42 mutations in exons 18, 19, 20 and 21 of the EGFR gene, including G719X, ex19del, S768I, T790M, exon 20 insertions, L858R and L861Q.

\subsection{Genotyping}

The whole blood samples were used to extract the genomic DNA using QIAamp DNA blood mini kits (Qiagen, Valencia, CA, USA) following the manufacturer's instructions. The polymorphisms of different antioxidant genes, SOD rs5746136 (assay IDs: C_29322854_10); SOD rs4880 (assay IDs: C__8709053_10); CAT rs769218 (assay IDs: C__3102900_10); OGG1 rs1052133 (assay IDs: C__3095552_1_); and TXN2 rs4821494 (assay IDs: C__2457432_10) were determined by real-time PCR genotyping using the ABI StepOne ${ }^{\mathrm{TM}}$ real-time PCR system (Applied Biosystems, Foster City, CA, USA). The results were analyzed using the StepOnePlus ${ }^{\mathrm{TM}}$ Software v2.3 (Applied Biosystems).

\subsection{Statistical Analysis}

The distributions of patient demographic features and genotype frequencies between wild-type and EGFR-mutated lung adenocarcinomas, as well as the clinicopathological features of EGFR-mutated lung adenocarcinoma patients in polymorphic genotypes of SOD rs4880 were analyzed by $\chi^{2}$-test. After controlling for other covariables, the odds ratio and 95\% CIs of the association between the genotype frequencies and EGFR mutation risk and the clinicopathological features were calculated using multiple logistic regression models. A $p$ value of $<0.05$ was considered statistically significant. All statistical analyses were carried out using SAS statistical software (Version 9.1, 2005; SAS Institute, Cary, NC, USA).

\section{Results}

\subsection{Demographic and Clinical Characteristics of Participants}

A total of 314 lung adenocarcinoma patients were enrolled for the study. Table 1 shows the demographic and clinical details of the participant. Of all participants, 117 had lung adenocarcinoma with wild-type EGFR (the WT group) and 197 had EGFR-mutated lung adenocarcinoma (the EGFR-mutated group). The average ages of the participants in the WT and EGFR-mutated groups were 65.7 and 65.1, respectively. There were statistically significant differences between the WT and EGFR-mutated groups in regard to gender, smoking status, tumor ' $\mathrm{T}$ ' classification and tumor differentiation. Than the WT group, the EGFR-mutated group had higher numbers of female (126 vs. 48 ) and non-smoker (158 vs. 57) participants. Moreover, the numbers of participants with well- (26 vs. 7 ) and moderately differentiated (158 vs. 89) tumors were higher in the EGFR-mutated group. 
Table 1. Distributions of demographical characteristics in 314 patients with lung adenocarcinoma by EGFR mutation status.

\begin{tabular}{|c|c|c|c|c|}
\hline \multirow[t]{2}{*}{ Variable } & Wild-Type & EGFR Mutation & Total & \multirow{2}{*}{$p$ Value } \\
\hline & $n=117(\%)$ & $n=197(\%)$ & $n=314$ & \\
\hline \multicolumn{5}{|l|}{ Age } \\
\hline$<30$ & $1(0.9)$ & $1(0.5)$ & 2 & \multirow[t]{6}{*}{0.673} \\
\hline $30-39$ & $2(1.7)$ & $2(1.0)$ & 4 & \\
\hline $40-49$ & $10(8.5)$ & $19(9.6)$ & 29 & \\
\hline $50-59$ & $23(19.7)$ & $54(27.4)$ & 77 & \\
\hline $60-69$ & $29(24.8)$ & $40(20.3)$ & 69 & \\
\hline$\geq 70$ & $52(44.4)$ & $81(47.1)$ & 133 & \\
\hline Mean \pm SD & $65.7 \pm 12.7$ & $65.1 \pm 13.2$ & & 0.512 \\
\hline \multicolumn{5}{|c|}{ Cigarette smoking } \\
\hline Non-smoker & $57(48.7)$ & $158(80.0)$ & 215 & \multirow[t]{2}{*}{$<0.001$ * } \\
\hline Smoker & $60(51.3)$ & $39(19.8)$ & 99 & \\
\hline \multicolumn{5}{|l|}{ Gender } \\
\hline Female & $48(41.0)$ & $126(64.0)$ & 174 & \multirow[t]{2}{*}{$<0.001$ * } \\
\hline Male & $69(59.0)$ & $71(36.0)$ & 140 & \\
\hline \multicolumn{5}{|c|}{ Tumor " $\mathrm{T}$ " classification } \\
\hline $\mathrm{T} 1$ & $21(17.9)$ & $43(21.8)$ & 64 & \multirow[t]{4}{*}{$0.001 *$} \\
\hline $\mathrm{T} 2$ & $42(35.9)$ & $85(43.1)$ & 127 & \\
\hline T3 & $27(23.1)$ & $14(7.1)$ & 41 & \\
\hline $\mathrm{T} 4$ & $27(23.1)$ & $55(27.9)$ & 82 & \\
\hline \multicolumn{5}{|c|}{ Lymph node status } \\
\hline Negative & $34(29.1)$ & $67(34.0)$ & 101 & \multirow[t]{2}{*}{0.364} \\
\hline Positive & $83(70.9)$ & $130(66.0)$ & 213 & \\
\hline \multicolumn{5}{|c|}{ Distant metastasis } \\
\hline Negative & $54(46.2)$ & $89(45.2)$ & 143 & \multirow[t]{2}{*}{0.867} \\
\hline Positive & $63(53.8)$ & $108(54.8)$ & 171 & \\
\hline \multicolumn{5}{|c|}{ Tumor AJCC staging } \\
\hline I & $23(19.7)$ & $45(22.8)$ & 68 & \multirow[t]{4}{*}{0.619} \\
\hline II & $7(6.0)$ & $8(4.1)$ & 15 & \\
\hline III & $24(20.5)$ & $32(16.2)$ & 56 & \\
\hline IV & $63(53.8)$ & $112(56.9)$ & 175 & \\
\hline \multicolumn{5}{|c|}{ Tumor differentiation } \\
\hline Well & $7(6.0)$ & $26(13.2)$ & 33 & \multirow[t]{3}{*}{$0.002 *$} \\
\hline Moderate & $89(76.1)$ & $158(80.2)$ & 247 & \\
\hline Poor & $21(17.9)$ & $13(6.6)$ & 34 & \\
\hline
\end{tabular}

$\mathrm{SD}$ is the abbreviation of standard Deviation. AJCC is the abbreviation of American Joint Committee on Cancer. The AJCC Cancer Staging Manual remains the gold standard reference for oncologists, surgeons, pathologists, radiologists, cancer registrars and medical professionals world-wide to ensure that all those caring for cancer patients are fully versed in the language of cancer staging. *: $p$ value is less than 0.05 .

\subsection{Distribution of Antioxidant Gene Polymorphisms of Participants and Its Association with EGFR Mutation}

Table 2 shows the distribution frequency of antioxidant gene polymorphisms (SOD rs5746136 and SOD rs4880; CAT rs769218; OGG1 rs1052133; and TXN2 rs4821494) of lung adenocarcinoma patients. The alleles with the highest distribution frequency for SOD rs5746136 and SOD rs4880 in study participants were homozygous C/C and homozygous A/A for both the WT and EGFR-mutated groups, respectively. For CAT rs769218; OGG1 rs1052133; and TXN2 rs4821494, the alleles with the highest distribution frequency among participants were homozygous $G / G$, homozygous $C / C$ and homozygous $\mathrm{G} / \mathrm{G}$, respectively, for both the WT and EGFR-mutated groups. For all antioxidant gene polymorphisms, there was no statistically significant association between different genotypes and EGFR mutation status in lung adenocarcinoma patients. 
Table 2. Distribution frequency of antioxidant gene polymorphism with lung adenocarcinoma and logistic regression of EGFR mutation association.

\begin{tabular}{|c|c|c|c|c|}
\hline Variable & Wild-Type & EGFR Mutation & AOR & $p$ Value \\
\hline & $n=117(\%)$ & $n=197(\%)$ & $95 \%$ CI & \\
\hline \multicolumn{5}{|c|}{$S O D$ rs5746136 } \\
\hline $\mathrm{CC}$ & $56(47.9)$ & $89(45.2)$ & 1.00 & \\
\hline $\mathrm{CT}$ & $45(38.5)$ & $75(38.1)$ & $1.06(0.63-1.76)$ & 0.833 \\
\hline $\mathrm{TT}$ & $16(13.7)$ & $33(16.8)$ & $1.40(0.69-2.84)$ & 0.347 \\
\hline $\mathrm{CT}+\mathrm{TT}$ & $61(62.1)$ & $108(5438)$ & $1.15(0.72-1.83)$ & 0.574 \\
\hline \multicolumn{5}{|l|}{$S O D$ rs4880 } \\
\hline AA & $88(75.2)$ & $133(67.5)$ & 1.00 & \\
\hline AG & $28(23.9)$ & $56(28.4)$ & $1.28(0.75-2.20)$ & 0.372 \\
\hline GG & $1(0.9)$ & $8(4.1)$ & $\begin{array}{c}4.96 \\
(0.60-41.20)\end{array}$ & 0.139 \\
\hline$A G+G G$ & $29(24.8)$ & $64(32.5)$ & $1.41(0.83-2.39)$ & 0.204 \\
\hline \multicolumn{5}{|c|}{ CAT rs769218 } \\
\hline GG & $61(52.1)$ & $99(50.3)$ & 1.00 & \\
\hline GA & $35(29.9)$ & $44(22.3)$ & $0.78(0.45-1.38)$ & 0.391 \\
\hline AA & $21(17.9)$ & $54(27.4)$ & $1.49(0.81-2.74)$ & 0.202 \\
\hline $\mathrm{GA}+\mathrm{AA}$ & $56(47.9)$ & $98(49.7)$ & $1.05(0.66-1.68)$ & 0.835 \\
\hline \multicolumn{5}{|c|}{ OGG1 rs1052133 } \\
\hline $\mathrm{CC}$ & $57(48.7)$ & $95(48.2)$ & 1.00 & \\
\hline CG & $40(34.2)$ & $67(34.0)$ & $0.96(0.57-1.62)$ & 0.870 \\
\hline GG & $20(17.1)$ & $35(17.8)$ & $0.89(0.46-1.73)$ & 0.729 \\
\hline $\mathrm{CG}+\mathrm{GG}$ & $60(51.3)$ & $102(51.8)$ & $0.93(0.58-1.50)$ & 0.777 \\
\hline \multicolumn{5}{|c|}{ TXN2 rs4821494 } \\
\hline GG & $55(47.0)$ & 107 (54.3) & 1.00 & \\
\hline GT & $54(46.2)$ & $73(37.1)$ & $0.62(0.42-1.13)$ & 0.143 \\
\hline $\mathrm{TT}$ & $8(6.8)$ & $17(8.6)$ & $1.07(0.42-2.70)$ & 0.892 \\
\hline $\mathrm{GT}+\mathrm{TT}$ & $62(53.0)$ & $90(45.7)$ & $0.74(0.46-1.19)$ & 0.211 \\
\hline
\end{tabular}

Adjusted odds ratios (AORs) with $95 \%$ confidence intervals (CIs) estimated by logistic models after controlling for age and gender.

3.3. Association between Antioxidant Gene Polymorphisms and EGFR Hotspot Mutations in Lung Adenocarcinoma

Table 3 represents the association between antioxidant gene polymorphisms (SOD rs5746136 and SOD rs4880; CAT rs769218; OGG1 rs1052133; and TXN2 rs4821494) and EGFR hotspot mutations in study participants. In the present study, two hotspot EGFR mutations including L858R and exon 19 in-frame deletions were evaluated. A significant association between L858R mutation and AG + GG genotypes of SOD rs4880 polymorphism was observed $(\mathrm{AOR}=1.90 ; 95 \% \mathrm{CI}=1.01-3.58 ; p=$ 0.047). However, there was no statistically significant association between $S O D$ rs 4880 genotypes and exon 19 in-frame deletions. For SOD rs5746136, CAT rs769218, OGG1 rs1052133 and TXN2 rs4821494 polymorphisms, no statistically significant association was observed between different genotypes and EGFR hotspot mutations. 
Table 3. Associations between antioxidant gene polymorphism and epidermal growth factor receptor hotspot mutations in lung adenocarcinoma.

\begin{tabular}{|c|c|c|c|c|c|c|c|}
\hline \multirow[t]{2}{*}{ Variable } & \multirow{2}{*}{$\begin{array}{l}\text { Wild-Type } \\
n=117(\%)\end{array}$} & \multicolumn{2}{|c|}{ Exon 19 in-Frame Deletion } & \multicolumn{4}{|c|}{ L858R } \\
\hline & & $n=96(\%)$ & AOR $(95 \% \mathrm{CI})$ & $p$ Value & $n=93(\%)$ & AOR $(95 \% \mathrm{CI})$ & $p$ Value \\
\hline \multicolumn{8}{|c|}{$S O D$ rs5746136 } \\
\hline $\mathrm{CC}$ & $56(47.9)$ & $45(46.9)$ & 1.00 & & $42(45.2)$ & 1.00 & \\
\hline $\mathrm{CT}$ & 45 (38.5) & $34(35.4)$ & $0.90(0.49-1.65)$ & 0.731 & 39 (41.9) & $1.29(0.69-2.41)$ & 0.433 \\
\hline TT & 16 (13.7) & 17 (17.7) & $1.41(0.63-3.16)$ & 0.401 & 12 (12.9) & $1.04(0.42-2.56)$ & 0.939 \\
\hline $\mathrm{CT}+\mathrm{TT}$ & $61(62.1)$ & $51(53.1)$ & $1.03(0.59-1.79)$ & 0.919 & $51(54.8)$ & $1.22(0.68-2.19)$ & 0.508 \\
\hline \multicolumn{8}{|c|}{$S O D$ rs 4880} \\
\hline AA & $88(75.2)$ & $70(72.9)$ & 1.00 & & $57(61.3)$ & 1.00 & \\
\hline AG & $28(23.9)$ & $23(24.0)$ & $0.95(0.50-1.83)$ & 0.884 & $31(33.3)$ & $1.69(0.88-3.25)$ & 0.114 \\
\hline GG & $1(0.9)$ & $3(3.1)$ & $3.68(0.36-37.90)$ & 0.273 & $5(5.4)$ & $8.68(0.85-89.12)$ & 0.069 \\
\hline $\mathrm{AG}+\mathrm{GG}$ & $29(24.8)$ & $26(27.1)$ & $1.04(0.56-1.96)$ & 0.894 & $36(38.7)$ & $1.90(1.01-3.58)$ & $0.047 *$ \\
\hline \multicolumn{8}{|c|}{ CAT rs769218 } \\
\hline GG & $61(52.1)$ & $50(52.1)$ & 1.00 & & $43(46.2)$ & 1.00 & \\
\hline GA & 35 (29.9) & $22(22.9)$ & $0.80(0.41-1.56)$ & 0.519 & $22(23.7)$ & $0.90(0.45-1.82)$ & 0.772 \\
\hline AA & $21(17.9)$ & $24(25.0)$ & $1.39(0.68-2.83)$ & 0.365 & $28(30.1)$ & $1.78(0.86-3.69)$ & 0.122 \\
\hline $\mathrm{GA}+\mathrm{AA}$ & $56(47.9)$ & $46(47.9)$ & $1.03(0.59-1.79)$ & 0.925 & $50(53.8)$ & $1.24(0.69-2.22)$ & 0.467 \\
\hline \multicolumn{8}{|c|}{ OGG1 rs1052133 } \\
\hline $\mathrm{CC}$ & $57(48.7)$ & $48(50.0)$ & 1.00 & & $44(47.3)$ & 1.00 & \\
\hline CG & $40(34.2)$ & $29(30.2)$ & $0.85(0.45-1.61)$ & 0.624 & $34(36.6)$ & $1.25(0.65-2.38)$ & 0.506 \\
\hline GG & 20 (17.1) & $19(19.8)$ & $0.98(0.46-2.11)$ & 0.965 & $15(16.1)$ & $0.88(0.38-2.01)$ & 0.757 \\
\hline CG + GG & $60(51.3)$ & $48(50.0)$ & $0.90(0.51-1.57)$ & 0.707 & 49 (52.7) & $1.11(0.62-1.99)$ & 0.723 \\
\hline \multicolumn{8}{|c|}{ TXN2 rs4821494 } \\
\hline GG & $55(47.0)$ & $54(56.3)$ & 1.00 & & 48 (51.6) & 1.00 & \\
\hline GT & 54 (46.2) & $37(38.5)$ & $0.69(0.39-1.23)$ & 0.206 & $33(35.5)$ & $0.65(0.35-1.21)$ & 0.176 \\
\hline TT & $8(6.8)$ & $5(5.2)$ & $0.71(0.21-2.36)$ & 0.575 & 12 (12.9) & $1.50(0.53-4.24)$ & 0.444 \\
\hline $\mathrm{GT}+\mathrm{TT}$ & $62(53.0)$ & $42(43.7)$ & $0.69(0.40-1.21)$ & 0.194 & 45 (48.4) & $0.76(0.42-1.37)$ & 0.367 \\
\hline
\end{tabular}

Adjusted odds ratios (AORs) with $95 \%$ confidence intervals (CIs) estimated by logistic regression models after controlling for age and gender. * $p$ value is less than 0.05 .

\subsection{Subgroup Analysis of EGFR Mutations Based on Polymorphic Genotypes of SOD rs4880}

To evaluate the correlation between clinicopathological features of EGFR hotspot mutations and SOD rs4880, a subgroup analysis of all lung adenocarcinoma cases as well as EGFR L858R and Exon 19 deletion mutations were performed (Table 4). The subgroup analysis data revealed that compared to AA genotype, AG + GG genotypes of SOD rs 4880 were associated with more aggressive lung adenocarcinoma phenotypes in terms of cancer staging, tumor size, lymph node status, distant metastasis and tumor differentiation. Moreover, a statistically significant correlation was observed between AG + GG genotypes and higher cancer staging irrespective of the EGFR mutation status. When considering all lung adenocarcinoma patients (WT and EGFR-mutated), AG + GG genotypes were found to correlate significantly with distant metastasis; however, similar statistically significant correlation was not observed for EGFR-mutated tumors. 
Table 4. Clinicopathologic characteristics of lung adenocarcinoma patients with EGFR mutation, stratified by polymorphic genotypes of SOD rs 4880 .

\begin{tabular}{|c|c|c|c|c|c|c|c|c|}
\hline \multicolumn{4}{|c|}{ All Cases $(n=306)$} & \multicolumn{5}{|c|}{ L858R and Exon 19 Deletion $(n=189)$} \\
\hline Variable & $\begin{array}{c}\text { AA } \\
(n=215)\end{array}$ & $\begin{array}{c}\mathrm{AG}+\mathrm{GG} \\
(n=91)\end{array}$ & $\begin{array}{c}\text { AOR } \\
(95 \% \text { CI })\end{array}$ & $p$ Value & $\begin{array}{c}\text { AA } \\
(n=127)\end{array}$ & $\begin{array}{c}\mathrm{AG}+\mathrm{GG} \\
(n=62)\end{array}$ & $\begin{array}{c}\text { AOR } \\
(95 \% \text { CI })\end{array}$ & $p$ Value \\
\hline \multicolumn{9}{|l|}{ Stage } \\
\hline $\mathrm{I}+\mathrm{II}$ & $66(30.7)$ & $15(16.5)$ & 1.00 & & $41(32.3)$ & $10(16.1)$ & 1.00 & \\
\hline III + IV & $149(69.3)$ & $76(83.6)$ & $2.24(1.20-4.22)$ & $0.012 *$ & $68(67.7)$ & $52(83.9)$ & $2.40(1.10-5.22)$ & $0.027 *$ \\
\hline \multicolumn{9}{|l|}{ Tumor T status } \\
\hline $\mathrm{T} 3+\mathrm{T} 4$ & $81(37.7)$ & $38(41.8)$ & $1.18(0.71-1.95)$ & 0.523 & $43(33.9)$ & $22(35.5)$ & $1.02(0.53-1.95)$ & 0.951 \\
\hline \multicolumn{9}{|l|}{ Lymph node status } \\
\hline Negative & $76(35.3)$ & $23(25.3)$ & 1.00 & & $48(37.8)$ & $17(27.4)$ & 1.00 & \\
\hline Positive & $139(64.7)$ & $68(74.7)$ & $1.63(0.94-2.84)$ & 0.084 & $79(62.2)$ & $45(72.6)$ & $0.56(0.80-3.30)$ & 0.195 \\
\hline \multicolumn{9}{|l|}{ Distant metastasis } \\
\hline Negative & $106(49.3)$ & $33(36.3)$ & 1.00 & & $63(49.6)$ & $22(35.5)$ & 1.00 & \\
\hline Positive & $109(50.7)$ & $58(63.7)$ & $1.69(1.01-2.80)$ & $0.044 *$ & $64(50.4)$ & $40(64.5)$ & $1.72(0.92-3.25)$ & 0.092 \\
\hline \multicolumn{9}{|l|}{ Tumor differentiation } \\
\hline Well & $24(11.2)$ & $7(7.7)$ & 1.00 & & $19(15.0)$ & $5(8.1)$ & 1.00 & \\
\hline Moderate + poor & $191(88.8)$ & $84(92.3)$ & $1.52(0.63-3.69)$ & 0.353 & $108(85.0)$ & $57(91.9)$ & $1.98(0.70-5.60)$ & 0.198 \\
\hline
\end{tabular}

\subsection{Subgroup Analysis of EGFR Mutations in Non-Smoking Patients Based on Polymorphic Genotypes of SOD $r s 4880$}

Finally, we evaluated the correlation between clinicopathological features in non-smoking NSCLC patients with EGFR mutations and SOD rs4880 (Table 5). The subgroup analysis data revealed that compared to AA genotype, AG + GG genotypes of SOD rs4880 were associated with more aggressive lung adenocarcinoma phenotypes in terms of cancer staging (III + IV). Moreover, a statistically significant correlation was observed between AG + GG genotypes and higher cancer staging with non-smoking status $(\mathrm{AOR}=3.15 ; 95 \% \mathrm{CI}=1.28-7.72 ; p=0.012$ ). Especially highly significant correlation was observed in female non-smoking populations ( $\mathrm{AOR}=3.55 ; 95 \% \mathrm{CI}=1.25-10.13 ; p=0.047$ ).

Table 5. Clinicopathologic characteristics of lung adenocarcinoma patients with EGFR mutation in non-smoking population, stratified by polymorphic genotypes of $S O D$ rs 4880 .

\begin{tabular}{|c|c|c|c|c|c|c|c|c|}
\hline \multirow[b]{2}{*}{ Variable } & \multicolumn{3}{|c|}{$\begin{array}{l}\text { EGFR Mutation in Non-Smoking } \\
\text { Cases }(n=155)\end{array}$} & \multicolumn{5}{|c|}{$\begin{array}{l}\text { EGFR Mutation in Female with } \\
\text { Non-Smoking Cases }(n=121)\end{array}$} \\
\hline & $\begin{array}{c}\text { AA } \\
(n=204)\end{array}$ & $\begin{array}{l}\mathrm{AG}+\mathrm{GG} \\
(n=51)\end{array}$ & $\begin{array}{c}\text { AOR } \\
(95 \% \mathrm{CI})\end{array}$ & $p$ Value & $\begin{array}{c}\text { AA } \\
(n=83)\end{array}$ & $\begin{array}{c}\mathrm{AG}+\mathrm{GG} \\
(n=38)\end{array}$ & $\begin{array}{c}\text { AOR } \\
(95 \% \mathrm{CI})\end{array}$ & $p$ Value \\
\hline \multicolumn{9}{|l|}{ Stage } \\
\hline $\mathrm{I}+\mathrm{II}$ & $35(33.7)$ & 7 (13.7) & 1.00 & & $30(36.1)$ & $5(13.2)$ & 1.00 & \\
\hline III+IV & $69(66.3)$ & $44(86.3)$ & $3.15(1.28-7.72)$ & $0.012 *$ & $53(63.9)$ & $33(86.8)$ & 3.55 (1.25-10.13) & $0.018^{*}$ \\
\hline $\mathrm{T} 3+\mathrm{T} 4$ & $35(33.7)$ & $18(35.3)$ & $1.06(0.53-2.15)$ & 0.865 & $26(31.3)$ & $14(36.8)$ & $1.19(0.53-2.71)$ & 0.671 \\
\hline \multicolumn{9}{|l|}{ Lymph node status } \\
\hline Negative & $41(39.4)$ & $14(27.5)$ & 1.00 & & $35(42.2)$ & $11(28.9)$ & 1.00 & \\
\hline Positive & $63(60.6)$ & $37(72.5)$ & $1.69(0.81-3.52)$ & 0.161 & $48(57.8)$ & $27(71.1)$ & $1.76(0.77-4.03)$ & 0.184 \\
\hline \multicolumn{9}{|l|}{ Distant metastasis } \\
\hline Negative & $52(50.0)$ & $18(35.3)$ & 1.00 & & $45(54.2)$ & $13(34.2)$ & 1.00 & \\
\hline
\end{tabular}

\section{Discussion}

The present study was designed to evaluate the association between antioxidant gene polymorphisms (SOD rs5746136 and SOD rs4880; CAT rs769218; OGG1 rs1052133; and TXN2 rs4821494) 
and EGFR-mutated lung adenocarcinoma. To the best of our knowledge, this is the first study of its kind, and the study findings may help identify more appropriate treatment approaches for better cancer management.

Our demographical and clinical data indicated that the number of female and non-smoker participants as well as participants with well- and moderately differentiated tumors was significantly higher in the EGFR-mutated group compared to that in the WT group (Table 1). While studying the distribution frequency of antioxidant gene polymorphisms in patients with WT- or EGFR-mutated lung adenocarcinoma, we found no statistically significant association between different polymorphic genotypes and EGFR mutation status (Table 2). The analysis performed to investigate the relationship between antioxidant gene polymorphisms with EGFR hotspot mutations (L858R and Exon 19 deletion mutations) revealed that a statistically significant association exists between L858R mutation and AG + GG genotypes of $S O D$ rs 4880 polymorphism (Table 3). Furthermore, our subgroup analysis data revealed that $A G+G G$ genotypes of $S O D$ rs 4880 were associated with more aggressive lung adenocarcinoma phenotypes compared to AA genotype of SOD rs4880. In particular, AG + GG genotypes were found to be correlated significantly with higher tumor stage and tumors with distant metastasis (Table 4). Additionally, we analyzed for clinical correlation in non-smoking NSCLC patients with EGFR mutations and SOD rs4880 (Table 5). Increased risk was observed in females; non-smokers; and with EGFR mutation.

The analysis of antioxidant gene polymorphisms in different cancer types has gained interest because of the significant impact of oxidant/antioxidant balance in the onset and progression of cancer $[26,27]$. There is a growing-pool of evidence suggesting that antioxidant gene polymorphisms are important predictors of cancer risks [18-20]. These studies have indicated that the distribution frequency of different polymorphic genotypes varies between different cancer subtypes, indicating the potential value of antioxidant gene polymorphisms as cancer biomarkers [28]. Moreover, genetic polymorphism-driven changes in the activity of cellular antioxidants can alter the therapeutic responsiveness of cancer patients through increased oxidative stress; thus, genetic polymorphism as a biomarker can be effective in identifying patient-specific therapeutic interventions and augmenting the responsiveness of personalized medicines [29]. The current findings showed that genetic variants in oxidative stress related genes may modify prognosis in EGFR TKIs-treated NSCLC patients. Cellular redox state is associated with the efficacy of EGFR TKIs treatment in NSCLC patients with activating EGFR mutations [21]. SOD2 overexpression was related to metastatic phenotype in cancers [30-32]. Several researchers have hypothesized that SOD2 overexpression promotes metastasis by increasing the steady-state concentration of $\mathrm{H} 2 \mathrm{O} 2$ [33,34]. In our findings, AG + GG genotypes of SOD rs 4880 were associated with more aggressive lung adenocarcinoma phenotypes compared to AA genotype of $S O D$ rs 4880 in advance NSCLC. Furthermore, we speculate that, AG + GG genotypes of SOD rs4880 increase SOD and promote NSCLC progression, especially in non-smoking female. Unfortunately, in this study, we do not have survival data to further validate the role of clinicopathological parameters in SNP by the Kaplan-Meier method or multivariate analysis.

Of all antioxidant genes, SOD genetic polymorphism is well-documented in the literature. SOD being the major first-line antioxidant neutralizes highly reactive superoxide free radicals into less reactive hydrogen peroxide [20]. In the present study, the in-depth analysis of the relationship between polymorphic genotypes of $S O D$ rs 4880 and clinic-pathologic features of EGFR-mutated lung adenocarcinoma is particularly important, because $S O D$ polymorphism-mediated stratification of EGFR mutation-related phenotypes, which are considered to be a major predictor of therapeutic responsiveness, can be more advantageous and effective in predicting lung cancer risk as well as therapeutic responsiveness.

\section{Conclusions}

The present study findings revealed that $S O D$ rs 4880 polymorphism is significantly associated with a specific EGFR hotspot mutation, L858R. Moreover, AG + GG polymorphic genotypes of SOD 
rs4880 are significant correlated with advancer cancer stage and distant metastasis in EGFR-mutated lung adenocarcinoma patients. These findings can be utilized clinically to predict cancer aggressiveness, metastatic potential and therapeutic responsiveness.

Author Contributions: C.-H.L., P.-J.Y., S.-H.L. (Shu-Hui Lin) and S.-F.Y. designed the project and experiments; S.-H.L. (Sheng-Hao Lin), K.-T.Y., T.C.-Y.T. and Y.-E.C. conducted the experiments and performed data analysis and made figures; S.-H.L. (Shu-Hui Lin) and S.-F.Y. wrote and revised the manuscript. All authors have read and agreed to the published version of the manuscript.

Funding: This study was funded by the Changhua Christian Hospital (104-CCH-IRP-099) of Taiwan.

Conflicts of Interest: The authors declare no conflict of interest.

\section{References}

1. Zappa, C.; Mousa, S.A. Non-small cell lung cancer: Current treatment and future advances. Transl. Lung Cancer Res. 2016, 5, 288-300. [CrossRef]

2. Sher, T.; Dy, G.K.; Adjei, A.A. Small Cell Lung Cancer. Mayo Clin. Proc. 2008, 83, 355-367. [CrossRef] [PubMed]

3. Wee, P.; Wang, Z. Epidermal Growth Factor Receptor Cell Proliferation Signaling Pathways. Cancers 2017, 9, 52. [CrossRef]

4. Santos, G.C.; Shepherd, F.A.; Tsao, M.-S. EGFR Mutations and Lung Cancer. Ann. Rev. Pathol. Mech. Dis. 2011, 6, 49-69. [CrossRef] [PubMed]

5. Bashir, N.A.; Ragab, E.S.; Khabour, O.F.; Khassawneh, B.Y.; Alfaqih, M.; Momani, J.A. The Association between Epidermal Growth Factor Receptor (EGFR) Gene Polymorphisms and Lung Cancer Risk. Biomolecules 2018, 8, 53. [CrossRef]

6. Castellanos, E.; Feld, E.; Horn, L. Driven by Mutations: The Predictive Value of Mutation Subtype in EGFR-Mutated Non-Small Cell Lung Cancer. J. Thorac. Oncol. 2017, 12, 612-623. [CrossRef]

7. Larsen, A.W.; Ebert, E.B.F.; Meldgaard, P.; Sorensen, B.S. EGFR Gene Polymorphism Predicts Improved Outcome in Patients With EGFR Mutation-positive Non-small cell Lung Cancer Treated With Erlotinib. Clin. Lung Cancer 2019, 20, 161-166.e1. [CrossRef] [PubMed]

8. He, L.; He, T.; Farrar, S.; Ji, L.; Liu, T.; Ma, X. Antioxidants Maintain Cellular Redox Homeostasis by Elimination of Reactive Oxygen Species. Cell. Physiol. Biochem. 2017, 44, 532-553. [CrossRef]

9. Wieczorek, E.; Jablonowski, Z.; Tomasik, B.; Gromadzinska, J.; Jablonska, E.; Konecki, T.; Fendler, W.; Sosnowski, M.; Wasowicz, W.; Reszka, E. Different Gene Expression and Activity Pattern of Antioxidant Enzymes in Bladder Cancer. Anticancer. Res. 2017, 37, 841-848. [CrossRef]

10. Harris, I.S.; Treloar, A.E.; Inoue, S.; Sasaki, M.; Gorrini, C.; Lee, K.C.; Yung, K.Y.; Brenner, D.; Knobbe-Thomsen, C.B.; Cox, M.A.; et al. Glutathione and Thioredoxin Antioxidant Pathways Synergize to Drive Cancer Initiation and Progression. Cancer Cell 2015, 27, 314. [CrossRef]

11. Lignitto, L.; Leboeuf, S.E.; Homer, H.; Jiang, S.; Askenazi, M.; Karakousi, T.R.; Pass, H.; Bhutkar, A.J.; Tsirigos, A.; Ueberheide, B.M.; et al. Nrf2 Activation Promotes Lung Cancer Metastasis by Inhibiting the Degradation of Bach1. Cell 2019, 178, 316-329.e18. [CrossRef] [PubMed]

12. Zalewska-Ziob, M.; Adamek, B.; Kasperczyk, J.; Romuk, E.; Hudziec, E.; Chwalińska, E.; Dobija-Kubica, K.; Rogoziński, P.; Bruliński, K. Activity of Antioxidant Enzymes in the Tumor and Adjacent Noncancerous Tissues of Non-Small-Cell Lung Cancer. Oxidative Med. Cell. Longev. 2019, 2019, 2901840. [CrossRef] [PubMed]

13. Sorokin, A.V.; Kotani, K.; Bushueva, O.Y.; Polonikov, A. Antioxidant-related gene polymorphisms associated with the cardio-ankle vascular index in young Russians. Cardiol. Young 2015, 26, 677-682. [CrossRef] [PubMed]

14. Zarafshan, S.S.; Salehi, Z.; Salahi, E.; Sabet, E.E.; Shabanipour, S.; Zahiri, Z. Polymorphism of catalase gene (CAT C-262T) in women with endometriosis. J. Obstet. Gynaecol. 2014, 35, 269-271. [CrossRef] [PubMed]

15. Banerjee, M.; Vats, P. Reactive metabolites and antioxidant gene polymorphisms in type 2 diabetes mellitus. Indian J. Hum. Genet. 2014, 20, 10-19. [CrossRef] 
16. Akyigit, A.; Keles, E.; Etem, E.O.; Ozercan, I.; Akyol, H.; Sakallioglu, O.; Karlidag, T.; Polat, C.; Kaygusuz, I.; Yalcin, S. Genetic polymorphism of antioxidant enzymes in eosinophilic and non-eosinophilic nasal polyposis. Eur. Arch. Oto-Rhino-Laryngol. 2016, 274, 267-273. [CrossRef]

17. Shen, Y.; Li, D.; Tian, P.; Shen, K.; Zhu, J.; Feng, M.; Wan, C.; Yang, T.; Chen, L.; Wen, F. The Catalase C-262T Gene Polymorphism and Cancer Risk. Medicine 2015, 94, e679. [CrossRef]

18. Kang, S.W. Superoxide dismutase 2 gene and cancer risk: Evidence from an updated meta-analysis. Int. J. Clin. Exp. Med. 2015, 8, 14647-14655.

19. Adibhesami, G.; Shahsavari, G.; Amiri, A.; Razavi, A.N.E.; Shamaei, M.; Birjandi, M. Glutathione S-transferase M1 (GSTM1) and T1 (GSTT1) Polymorphisms and Lung Cancer Risk among a Select Group of Iranian People. Asian Pac. J. Cancer Prev. 2018, 19, 2921-2927.

20. Zejnilovic, J.; Akev, N.; Yilmaz, H.; Isbir, T. Association between manganese superoxide dismutase polymorphism and risk of lung cancer. Cancer Genet. Cytogenet. 2009, 189, 1-4. [CrossRef]

21. Xu, Y.; Pan, Q.; Wang, C.; He, C.; Su, Z.; Guo, X.; Zhang, J.; Kong, M.; Ke, S.; Zhang, J.; et al. Genetic polymorphisms in oxidative stress-related genes are associated with clinical outcome in patients with advanced non-small cell lung cancer receiving tyrosine kinase inhibitors. Am. J. Cancer Res. 2014, 4, 934-942.

22. Giordano, C.R.; Mueller, K.L.; Terlecky, L.J.; Krentz, K.A.; Bollig, A.; Terlecky, S.R.; Boerner, J.L. A targeted enzyme approach to sensitization of tyrosine kinase inhibitor-resistant breast cancer cells. Exp. Cell Res. 2012, 318, 2014-2021. [CrossRef] [PubMed]

23. Cebrián, A.; Pharoah, P.D.; Ahmed, S.; Smith, P.; Luccarini, C.; Luben, R.N.; Redman, K.; Munday, H.; Easton, D.F.; Dunning, A.M.; et al. Tagging Single-Nucleotide Polymorphisms in Antioxidant Defense Enzymes and Susceptibility to Breast Cancer. Cancer Res. 2006, 66, 1225-1233. [CrossRef] [PubMed]

24. Miar, A.; Hevia, D.; Muñoz-Cimadevilla, H.; Astudillo, A.; Velasco, J.; Sainz, R.M.; Mayo, J.C. Manganese superoxide dismutase (SOD2/MnSOD)/catalase and SOD2/GPx1 ratios as biomarkers for tumor progression and metastasis in prostate, colon, and lung cancer. Free. Radic. Boil. Med. 2015, 85, 45-55. [CrossRef] [PubMed]

25. Seibold, P.; Hein, R.; Schmezer, P.; Hall, P.; Liu, J.; Dahmen, N.; Flesch-Janys, D.; Popanda, O.; Chang-Claude, J. Polymorphisms in oxidative stress-related genes and postmenopausal breast cancer risk. Int. J. Cancer 2011, 129, 1467-1476. [CrossRef]

26. Chikara, S.; Nagaprashantha, L.D.; Singhal, J.; Horne, D.; Awasthi, S.; Singhal, S.S. Oxidative stress and dietary phytochemicals: Role in cancer chemoprevention and treatment. Cancer Lett. 2018, 413, 122-134. [CrossRef]

27. Kudryavtseva, A.V.; Krasnov, G.S.; Dmitriev, A.A.; Alekseev, B.Y.; Kardymon, O.; Sadritdinova, A.F.; Fedorova, M.S.; Pokrovsky, A.V.; Melnikova, N.V.; Kaprin, A.D.; et al. Mitochondrial dysfunction and oxidative stress in aging and cancer. Oncotarget 2016, 7, 44879-44905. [CrossRef]

28. Chan, J.M.; Darke, A.K.; Penney, K.L.; Tangen, C.M.; Goodman, P.J.; Lee, G.-S.M.; Sun, T.; Peisch, S.; Tinianow, A.M.; Rae, J.M.; et al. Selenium- or vitamin E-related gene variants, interaction with supplementation, and risk of high-grade prostate cancer in SELECT. Cancer Epidemiol. Biomark. Prev. 2016, 25, 1050-1058. [CrossRef]

29. Shiota, M.; Fujimoto, N.; Itsumi, M.; Takeuchi, A.; Inokuchi, J.; Tatsugami, K.; Yokomizo, A.; Kajioka, S.; Uchiumi, T.; Eto, M. Gene polymorphisms in antioxidant enzymes correlate with the efficacy of androgen-deprivation therapy for prostate cancer with implications of oxidative stress. Ann. Oncol. 2017, 28, 569-575. [CrossRef]

30. Liu, Z.; Li, S.; Cai, Y.; Wang, A.; He, Q.; Zheng, C.; Zhao, T.; Ding, X.; Zhou, X. Manganese superoxide dismutase induces migration and invasion of tongue squamous cell carcinoma via H2O2-dependent Snail signaling. Free. Radic. Boil. Med. 2012, 53, 44-50. [CrossRef]

31. Kattan, Z.; Minig, V.; Leroy, P.; Dauça, M.; Becuwe, P. Role of manganese superoxide dismutase on growth and invasive properties of human estrogen-independent breast cancer cells. Breast Cancer Res. Treat. 2007, 108, 203-215. [CrossRef] [PubMed]

32. Chang, B.; Yang, H.; Jiao, Y.; Wang, K.; Liu, Z.; Wu, P.; Li, S.; Wang, A. SOD2 deregulation enhances migration, invasion and has poor prognosis in salivary adenoid cystic carcinoma. Sci. Rep. 2016, 6, 25918. [CrossRef] [PubMed] 
33. Ranganathan, A.C.; Nelson, K.K.; Rodriguez, A.M.; Kim, K.H.; Tower, G.B.; Rutter, J.L.; Brinckerhoff, C.E.; Huang, T.T.; Epstein, C.J.; Jeffrey, J.J.; et al. Manganese superoxide dismutase signals matrix metalloproteinase expression via H2O2-dependent ERK1/2 activation. J. Biol. Chem. 2001, 276, 14264-14270. [CrossRef]

34. Yoo, D.G.; Song, Y.J.; Cho, E.J.; Lee, S.-K.; Park, J.B.; Yu, J.H.; Lim, S.P.; Kim, J.M.; Jeon, B.H. Alteration of APE1/ref-1 expression in non-small cell lung cancer: The implications of impaired extracellular superoxide dismutase and catalase antioxidant systems. Lung Cancer 2008, 60, 277-284. [CrossRef] [PubMed]

(C) 2020 by the authors. Licensee MDPI, Basel, Switzerland. This article is an open access article distributed under the terms and conditions of the Creative Commons Attribution (CC BY) license (http://creativecommons.org/licenses/by/4.0/). 